\title{
Microdetermination of Unsaturated Disaccharides Produced from Chondroitin Sulfates in Rabbit Plasma by High Performance Liquid Chromatography with Fluorometric Detection
}

\author{
Hidenao Toyoda, Kazufusa Shinomiya, Shigeyuki YamanaShI, Ichiro Koshishi and Toshio ImanarI \\ Faculty of Pharmaceutical Sciences, Chiba University, Yayoi-cho, Chiba 260
}

\begin{abstract}
A highly sensitive high performance liquid chromatographic method with fluorometric postcolumn labeling using 2-cyanoacetamide was developed for determination of unsaturated disaccharides produced enzymatically from chondroitin sulfates $(\mathrm{ChS})$. The calibration curves of the unsaturated disaccharides were linear over the range from 2 pmol to $5 \mathrm{nmol}$. This method was applied to the analysis of normal rabbit plasma for $\mathrm{ChS}$ to verity the sensitivity and practicality.
\end{abstract}

Keywords Unsaturated disaccharide, chondroitin sulfate, glycosaminoglycan, high performance liquid chromatography, 2-cyanoacetamide

Very small amounts of glycosaminoglycans (GAGs) are reported in mammalian plasma..$^{1,2} \mathrm{~A}$ major constituent of GAGs is low-sulfated chondroitin 4sulfate. ${ }^{3}$ To elucidate the physiological roles of GAGs, many workers have studied analytical methods for determination of GAGs in plasma or serum using chromatography ${ }^{4}$ and electrophoresis. ${ }^{3,5,6}$

Recently, high-performance liquid chromatographic (HPLC) methods have been developed with $\mathrm{UV}^{7-10}$ or fluorometric precolumn labeling method" after converting GAGs to their corresponding unsaturated disaccharides by enzymatic digestion. Those methods are not suitable for the determination of chondroitin sulfates (ChS) in plasma. UV detection at $232 \mathrm{~nm}$ for unsaturated disaccharides is not sensitive enough, and the fluorometric precolumn detection using the 2aminopyridine derivatives ${ }^{11}$ requires time-consuming and tedious sample preparation.

In this reseach, we studied highly sensitive HPLC methods for determination of unsaturated disaccharides, with fluorometric postcolumn labeling using 2cyanoacetamide, which was introduced by Honda $e t$ al. ${ }^{12}$ Then we tried to apply the method to the analysis of rabbit plasma for small amounts of $\mathrm{ChS}$.

\section{Experimental}

\section{Reagents and materials}

Standard unsaturated disaccharides (2-acetamido-2deoxy-3- $O$-( $\beta$-D-gluco-4-enepyranosyluronic acid)-D-galactose ( $\triangle \mathrm{Di}-0 \mathrm{~S}), 2$-acetamido-2-deoxy-3-O-( $\beta$-D-gluco4-enepyranosyluronic acid)-4- $O$-sulfo-D-galactose ( $\triangle \mathrm{Di}$ $4 S)$ and 2-acetamido-2-deoxy-3-O-( $\beta$-D-gluco-4-enepy- ranosyluronic acid)-6-sulfo-D-galactose ( $\triangle \mathrm{Di}-6 \mathrm{~S})$ ) and chondroitinase $A B C$ (EC 4.2.2.4) were obtained from Seikagaku Kogyo Co. (Tokyo, Japan). 2-Cyanoacetamide was purchased from Kanto Chemicals (Tokyo, Japan), and pronase from Kaken Pharmaceutical Co. (Tokyo, Japan). All other chemicals were of reagent grade. TSK gel $\mathrm{NH}_{2} 60$ (Toyo Soda Co., Tokyo, Japan) of particle size $5 \mu \mathrm{m}$ was packed in a stainless tube ( $3 \mathrm{~mm}$ i.d. $\times 250 \mathrm{~mm}$ ).

\section{Apparatus and chromatographic conditions}

The chromatographic equipment included a reciprocating pump (PSU-2.5 W, Seishin Pharmaceutical Co., Tokyo, Japan), a double plunger pump for the reagent solution (SPU-2.5 W, Shimamura instrument Co., Tokyo, Japan), a sample injector (VMD-350, Shimamura instrument Co.), a fluoromonitor (RF-530 fluorescence spectromonitor, Shimadzu Seisakusho, Kyoto, Japan), a variable input recorder (SS-250F, Sekonic Co., Tokyo, Japan) and a dry reaction bath (Type DB-3, Shimamura Instrument Co.). A UV monitor (UVILOG-7, Oyo-Bunko Kiki Co., Tokyo, Japan) was used for the detection at $232 \mathrm{~nm}$.

Established HPLC conditions were as follows: A $10 \mu \mathrm{l}$ portion of sample solution was loaded via a sample injector with a $20 \mu \mathrm{l}$ loop. A TSK gel $\mathrm{NH}_{2} 60$ column $(3.0 \mathrm{~mm}$ i.d. $\times 250 \mathrm{~mm})$ was eluted with $10 \mathrm{mM}$ ammonium formate buffer (pH 5.0) containing $10 \mathrm{mM}$ sodium sulfate in $4 \%$ acetonitrile at a flow rate of $0.5 \mathrm{ml} / \mathrm{min}$. To the eluate were added $0.125 \mathrm{M}$ sodium tetraborate-sodium hydroxide buffer (pH 10.8) and aqueous $1 \%$ 2-cyanoacetamide solution at a flow rate of $0.2 \mathrm{ml} / \mathrm{min}$ by using a double-plunger pump. The mixture passed through a polytetrafluoroethylene 
(PTFE) reaction coil $(0.5 \mathrm{~mm}$ i.d. $\times 10 \mathrm{~m})$ set in a dry reaction bath thermostated at $100^{\circ} \mathrm{C}$ and a following PTFE cooling coil $(0.25 \mathrm{~mm}$ i.d. $\times 2 \mathrm{~m})$ in a water bath at $25^{\circ} \mathrm{C}$. The effluent was monitored by the fluoromonitor (Ex. 346 nm, Em. 410 nm).

\section{Collection of rabbit plasma}

Blood was collected from the marginal ear vein of adult rabbits. Ethylenediaminetetraacetic acid disodium salt was added to the blood as an anticoagulant. The blood was separated into plasma and cells by centrifugation at $1200 \times \mathrm{g}$ for $15 \mathrm{~min}$; the plasma was then transferred to a tube.

\section{Preparation of plasma GAGs}

Plasma GAGs were separated by a modification of the method of Emura and Mukuda ${ }^{13}$ as follows: To $100 \mu \mathrm{l}$ of rabbit plasma, $40 \mu \mathrm{l}$ of $0.05 \mathrm{M}$ Tris- $\mathrm{HCl}$ buffer (pH 8.0) containing $1 \%$ pronase was added, and the mixture was incubated at $45^{\circ} \mathrm{C}$ for $3 \mathrm{~h}$. To the solution, $340 \mu \mathrm{l}$ of $12 \%$ sodium chloride solution and $60 \mu \mathrm{l}$ of $0.1 \mathrm{M}$ acetic acid solution were added. Then the mixture was heated in a boiling water bath for $5 \mathrm{~min}$. After being cooled in a water bath, the solution was centrifuged at $2300 \times g$ for $15 \mathrm{~min}$. To $360 \mu \mathrm{l}$ of the supernatant, $40 \mu \mathrm{l}$ of $0.1 \mathrm{M}$ sodium hydroxide solution and $1.6 \mathrm{ml}$ of cooled ethanol saturated with sodium acetate were added. The mixture was left to stand at $5^{\circ} \mathrm{C}$ for $1 \mathrm{~h}$ and centrifuged at $2300 \times \mathrm{g}$ for $15 \mathrm{~min}$. To the precipitate was added $0.6 \mathrm{ml}$ of $0.015 \%$ cetylpyridinium chloride containing $0.03 \mathrm{M}$ sodium chloride warmed at $37^{\circ} \mathrm{C}$ before use. The mixture was left to stand overnight at $0^{\circ} \mathrm{C}$. The solution was centrifuged at $2300 \times g$ for $15 \mathrm{~min}$ at $5^{\circ} \mathrm{C}$. The precipitate was washed twice with $0.6 \mathrm{ml}$ of ethanol saturated with sodium chloride, and then lyophilized.

\section{Enzymatic digestion}

Digestion of plasma GAGs with chondroitinase ABC was carried out according to the method ${ }^{14}$ of Kodama et al.

\section{Results and Discussion}

Chromatographic separation and detection of unsaturated disaccharides

Separation of $\Delta \mathrm{Di}-0 \mathrm{~S}, \Delta \mathrm{Di}-4 \mathrm{~S}$ and $\Delta \mathrm{Di}-6 \mathrm{~S}$ was successfully performed by some workers on aminosilca type columns with acidic (pH 4-6) ${ }^{8,10}$ eluents. Considering the postcolumn method with 2-cyanoacetamide which is reacted with the unsaturated disaccharides in weakly alkali solution, the concentration of salts in an eluent was decreased to change the $\mathrm{pH}$ of effluent. The unsaturated disaccharides were resolved within 20 min on the TSK gel $\mathrm{NH}_{2} 60$ column with $10 \mathrm{mM}$ ammonium formate buffer (pH 5.0) containing $10 \mathrm{mM}$ sodium sulfate in $4 \%$ acetonitrile as an eluent (Fig. 1). The detection system was set by the modi- fication of Honda's method ${ }^{12}$ using 2-cyanoacetamide as a detection reagent. The fluorescence intensities of unsaturated disaccharides were examined by a flow injection system without the separation column. The excitation and emission wavelengths were set to $346 \mathrm{~nm}$ and $410 \mathrm{~nm}$, respectively, for the determination of unsaturated disaccharides, while neutral sugars had the maximum fluorescence intensities at $331 \mathrm{~nm}$ (Ex.) and $383 \mathrm{~nm}(\mathrm{Em}$.$) . As shown in Table 1, relative$ fluorescence intensities of $\triangle \mathrm{Di}-0 \mathrm{~S}, \Delta \mathrm{Di}-4 \mathrm{~S}$ and $\triangle \mathrm{Di}-6 \mathrm{~S}$

Table 1 Comparison of fluorescence intensities formed from various carbohydrates using flow injection analysis

\begin{tabular}{lc}
\multicolumn{1}{c}{ Carbohydrate } & $\begin{array}{c}\text { Relative molar } \\
\text { fluorescence intensity }\end{array}$ \\
\cline { 2 - 2 } & (Ex. 346 nm)/(Em. 410 nm) \\
\hline D-Glucose & 1 \\
D-Galactose & 1 \\
D-Glucosamine HCl & 7 \\
D-Galactosamine HCl & 4 \\
D-Glucuronic acid & 7 \\
D-Galacturonic acid & 19 \\
N-Acetyl-D-glucosamine & 22 \\
N-Acetyl-D-galactosamine & 61 \\
DDi-0S & 398 \\
DDi-4S & 436 \\
DDi-6S & 456 \\
\hline
\end{tabular}

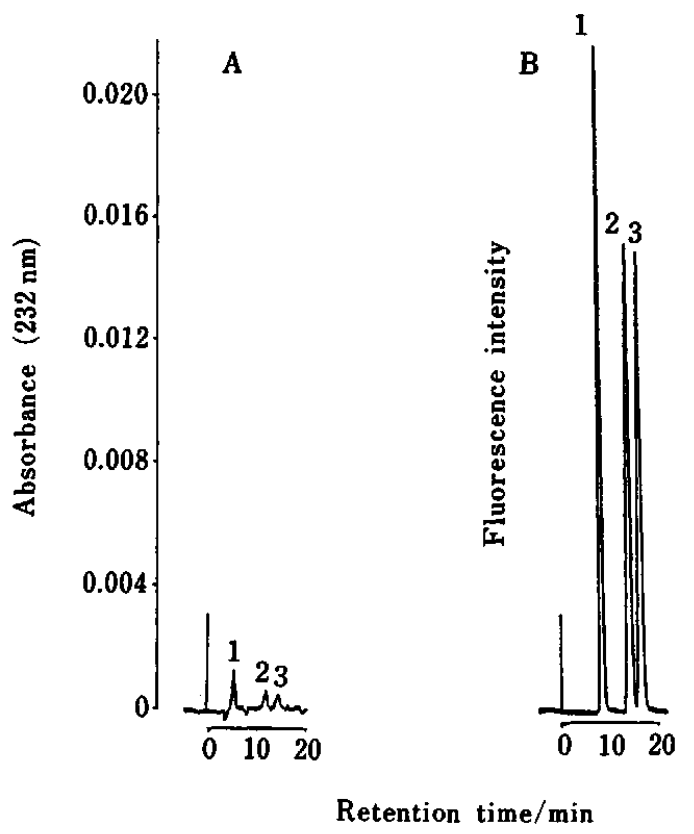

Fig. 1 Typical chromatograms of standard unsaturated disaccharides. A, UV detection at $232 \mathrm{~nm}$ (The separation system is the same as that in the postcolumn labeling method (B).); B, fluorometric detection using 2-cyanoacetamide (The other conditions are shown in the experimental section.); sample size, $10 \mu \mathrm{l}$ (50 ng of each sugar). Peaks: 1, $\triangle \mathrm{Di}-0 \mathrm{~S} ; 2, \triangle \mathrm{Di}-6 \mathrm{~S} ; 3, \triangle \mathrm{Di}-4 \mathrm{~S}$. 
were about 300-400 times stronger than those of neutral sugars in our system.

Calibration curves for $\triangle \mathrm{Di}-0 \mathrm{~S}, \triangle \mathrm{Di}-4 \mathrm{~S}$ and $\triangle \mathrm{Di}-6 \mathrm{~S}$ were linear in the ranges of $2 \mathrm{pmol}-5 \mathrm{nmol}, 4 \mathrm{pmol}$ -

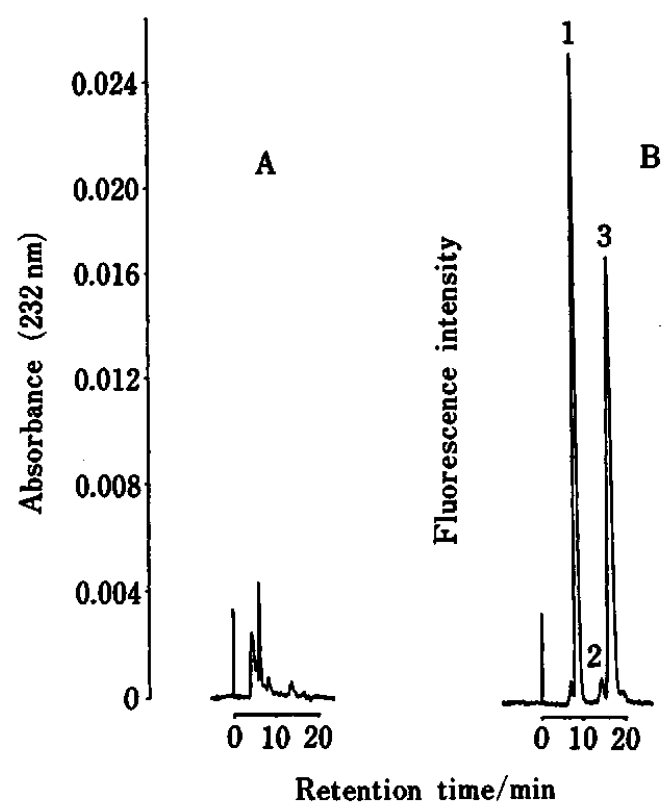

Fig. 2 Chromatograms of unsaturated disaccharides produced from rabbit plasma GAGs. A, UV detection at $232 \mathrm{~nm}$; B, fluorometric detection using 2-cyanoacetamide; sample size, $10 \mu$ l. Peaks: $1, \Delta \mathrm{Di}-0 \mathrm{~S} ; 2, \Delta \mathrm{Di}-6 \mathrm{~S} ; 3, \Delta \mathrm{Di}-4 \mathrm{~S}$.
$5 \mathrm{nmol}$ and $4 \mathrm{pmol}-5 \mathrm{nmol}$ respectively. The sensitivity of this method was about 20 times higher than that of UV detection as shown in Fig. 1. The relative standard deviations $(n=7)$ of $\Delta \mathrm{Di}-0 \mathrm{~S}, \Delta \mathrm{Di}-4 \mathrm{~S}$ and $\Delta \mathrm{Di}-6 \mathrm{~S}$ were $1.5,1.4$ and $1.8 \%$, respectively.

\section{Analysis of rabbit plasma ChS}

The present method was applied to the determination of unsaturated disaccharides produced from normal rabbit plasma $\mathrm{ChS}$ by chondroitinase $\mathrm{ABC}$ digestion. Figure 2 shows typical chromatograms of unsaturated disaccharides produced from plasma $\mathrm{ChS}$. The peaks of $\triangle \mathrm{Di}-0 \mathrm{~S}, \triangle \mathrm{Di}-4 \mathrm{~S}$ and $\triangle \mathrm{Di}-6 \mathrm{~S}$ were detected with postcolumn labeling using 2-cyanoacetamide (Fig. 2B), while they could not be detected with UV detection at $232 \mathrm{~nm}$ (Fig. 2A). The unsaturated disaccharides mainly produced from plasma $\mathrm{ChS}$ were $\triangle \mathrm{Di}-0 \mathrm{~S}$ and $\triangle \mathrm{Di}-4 \mathrm{~S}$. This result indicates that lowsulfated chondroitin 4-sulfate is present in plasma.

Variation of $\mathrm{ChS}$ concentration in a rabbit plasma within a month were estimated from the amounts of $\triangle \mathrm{Di}-0 \mathrm{~S}, \triangle \mathrm{Di}-4 \mathrm{~S}$ and $\triangle \mathrm{Di}-6 \mathrm{~S}$ (Table 2). The data shows that concentrations of plasma $\mathrm{ChS}$ are fairly constant in a rabbit. Moreover, analytical results of ChS concentrations in rabbit plasma are shown in Table 3. It is very interesting that no differences of ChS concentrations could be found among individual rabbits. The occurrence of low-sulfated chondroitin 4sulfate, which is composed of both $\triangle \mathrm{Di}-0 \mathrm{~S}$ and $\triangle \mathrm{Di}$ $\mathbf{4 S}$, is of interest in particular with regard to the process

Table 2 Variation of unsaturated disaccharides produced from chondroitin sulfates in a normal rabbit plasma after digestion with chondroitinase $\mathrm{ABC}$

\begin{tabular}{|c|c|c|c|c|}
\hline \multirow{2}{*}{ Plasma } & \multicolumn{3}{|c|}{ Unsaturated disaccharide $/ \mu \mathrm{M}$} & \multirow{2}{*}{ Total amount $/ \mu \mathrm{M}$} \\
\hline & $\triangle \mathrm{Di}-0 \mathrm{~S}$ & $\Delta \mathrm{Di}-4 \mathrm{~S}$ & $\Delta \mathrm{Di}-6 \mathrm{~S}$ & \\
\hline A-1 & $9.30(51.7)$ & $8.25(45.8)$ & $0.45(2.5)$ & 18.00 \\
\hline$A-2$ & $9.40(49.9)$ & $9.00(47.7)$ & $0.45(2.4)$ & 18.85 \\
\hline A-3 & $9.00(47.2)$ & $9.60(50.3)$ & $0.47(2.5)$ & 19.07 \\
\hline A-4 & $8.70(47.6)$ & $9.10(49.8)$ & $0.47(2.6)$ & 18.27 \\
\hline A-5 & $8.10(46.3)$ & $9.00(51.4)$ & $0.41(2.3)$ & 17.51 \\
\hline Mean士 S.D. & $8.90 \pm 0.47$ & $8.99 \pm 0.43$ & $0.45 \pm 0.02$ & $18.34 \pm 0.56$ \\
\hline
\end{tabular}

The values in the parentheses represent the proportions (\%) of the disaccharide to the total amount of unsaturated disaccharides.

Table 3 Determination of unsaturated disacharides produced from chondroitin sulfates in normal rabbit plasma after digestion with chondroitinase $\mathbf{A B C}$

\begin{tabular}{|c|c|c|c|c|}
\hline \multirow{2}{*}{ Rabbit } & \multicolumn{3}{|c|}{ Unsaturated disaccharide $/ \mu \mathrm{M}$} & \multirow{2}{*}{ Total amount $/ \mu \mathrm{M}$} \\
\hline & $\triangle \mathrm{Di}-0 \mathrm{~S}$ & $\Delta \mathrm{Di}-4 \mathrm{~S}$ & $\Delta \mathrm{Di}-6 \mathrm{~S}$ & \\
\hline $\mathbf{A}$ & $9.30(51.7)$ & $8.25(45.8)$ & $0.45(2.5)$ & 18.00 \\
\hline B & $10.76(57.9)$ & $7.45(40.1)$ & $0.38(2.0)$ & 18.59 \\
\hline $\mathbf{C}$ & $11.12(55.2)$ & $8.2(41.1)$ & $0.76(3.8)$ & 20.14 \\
\hline D & $9.15(48.7)$ & 8.89 (47.3) & $0.74(4.0)$ & 18.78 \\
\hline $\mathbf{E}$ & $9.72(45.1)$ & $11.11(51.5)$ & $0.74(3.4)$ & 21.57 \\
\hline Mean \pm S.D. & $10.01 \pm 0.79$ & $8.79 \pm 1.25$ & $0.61 \pm 0.16$ & $19.42 \pm 1.28$ \\
\hline
\end{tabular}

The values in the parentheses represent the proportions $(\%)$ of the disaccharide to the total amount of unsaturated disaccharides. 
of sulfation.

As described above, this sensitive chromatographic method was first applied to the determination of ChS in small amounts of plasma sample. This method is effective for the determination of trace amounts of hyaluronic acid, heparan sulfate and keratan sulfate after the specific enzymatic digestion.

\section{References}

1. J. Badin and M. Schubert, J. Clin. Invest., 34, 1312 (1955).

2. A. Calatroni, P. V. Donnelly and N. DiFerrante, J. Clin. Invest., 48, 332 (1969).

3. N. Taniguchi, N. Moriya and I. Nanba, Clin. Chim. Acta, 50, 319 (1974).

4. I. Staprans and J. M. Felts, J. Clin. Invest., 76, 1984 (1985).

5. K. Murata and Y. Yokoyama, Clin. Chim. Acta, 75, 59 (1977).
6. I. Staprans, J. M. Felts and R. J. Butts, Anal. Biochem., 134, 240 (1983).

7. K. Murata and Y. Yokoyama, Anal. Biochem., 146, 327 (1985).

8. J. Macek, J. Krajickova and M. Adam, J. Chromatogr., 414, 156 (1987).

9. K. Murata and Y. Yokoyama, J. Chromatogr., 415, 231 (1987).

10. T. Gherezghiher, M. C. Koss, R. E. Nordquist and C. P. Wilkinson, J. Chromatogr., 413, 9 (1987).

11. C. Kodama, N. Ototani, M. Isemura and Z. Yosizawa, $J$. Biochem., 96, 1283 (1984).

12. S. Honda, Y. Matsuda, M. Takahashi and K. Kakehi, Anal. Chem., 52, 1079 (1980).

13. Y. Emura and T. Mukuda, Seikagaku, 45, 30 (1973).

14. C. Kodama, N. Ototani, M. Isemura, J. Aikawa and Z. Yosizawa, Clin. Chem., 32, 30 (1986).

(Received March 5, 1988)

(Accepted June 7, 1988) 